\section{COMPOSITE MATERIALS}

\section{Strong Fibrous Solids}

\section{from our Materials Science Correspondent}

THE growing interest and importance of strong fibrous solids were underlined by the Royal Society's discussion on this topic held in London on January 29. Mr W. Watt (Royal Aircraft Establishment, Farnborough) summarized the structural changes believed to take place in polyacrylonitrile (PAN) fibres during progressive heating in oxidizing or neutral atmospheres, with or without tensile stress, and the associated changes in properties at each stage. $\mathrm{He}$ emphasized that the statistical variability in tensile strength depcnded substantially on sample length, which indicates the importance of defects in limiting the strength. It is uncertain whether the vital defects are the inclusions, or the elongated pores recently established by diffuse X-ray scattering and electron microscopy. Watt stressed the paucity of knowledge about structural changes in PAN, for example, concerning the degree of crystallinity induced by drawing, and called for intensive investigation. The opinion was often expressed at the meeting that the technology of fibre composites has too far outstripped scientific understanding.

Dr R. J. E. Glenny (National Gas Turbine Establishment, Farnborough) recounted systematic experiments on the use of fibre composites based on refractory matrices specifically for use in gas turbine blades. On the basis of the criteria of density, strength and chemical compatibility, attention was focused on a nickelbase matrix with wires of tungsten or tungsten/ rhenium alloy, Mo-RTZ alloy or alumina. Vacuumcasting of blade shapes in a cored shell-mould gave excellently uniform filament distribution and it proved possible to incorporate clear channels for coolant. Tungsten and alumina were the most promising reinforcements. Strength levels were marginally less than predicted by the rule of mixtures, and fatigue behaviour was little affected by the presence of filaments. It is too soon to be sure of the future scope of these techniques, but in view of the fact that niobium and chromium alloys are not considered to be equal to expectations filament-reinforcement seems to be the most promising way to improve on the intrinsic properties of nickel superalloys.

Dr J. Nixdorf (Battelle-Institut, Frankfurt) described the pilot-plant production of various strong metallic microwires, including wire of a marageing steel. The technique involves melting a metal rod held in a viscous glass mantle (which acts as both container and lubricant) and rapidly drawing the assembly through a die. Afterwards the glass covering is removed. The strength is attributed not only to the small diameter of a few microns but also to the rapid cooling. A particularly small statistical variability of the wire strength was claimed, and the mean strength exceeded that of boron but was less than that of E-glass. Little was said about stiffness. Various composites have been made with both metallic and polymeric matrices, and for concentrated composites a UTS better than for boron or carbon reinforcement was claimed. The production cost of microwires (on a scale resembling the present scale of production of carbon fibres) was assessed at some tens of pounds sterling per $\mathrm{kg}$. Oddly enough, the audience made no reaction to these intriguing disclosures. Describing the development of 'Hyfil' (carbon fibrereinforced) compressor blades in Rolls-Royce jet engines, Mr J. I. Goatham (Rolls-Royce, Derby) emphasized the extensive testing procedures needed, both for development and for routine testing, including such exotic methods as holography. He also mentioned the great importance of joints and attachments, where critical losses of weight advantage can easily be sustained by faulty design. He was the only speaker to emphasize the joining problem, though the chairman, Dr A. H. Cottrell (Cabinet Office, London), expressed the view that this central problem was well on the way to being vanquished.

Dr F. J. McGarry (Massachusetts Institute of Technology) reported work on epoxy resin toughened by elastomer dispersions-following the example of rubber-reinforced polystyrene described at the Royal Society in 1963. The impressive increase in fracture toughness which was achieved seemed to depend in part on achieving an optimal degree of cross-linking of the elastomer, as well as a bimodal distribution of coarse and fine elastomer particles. McGarry postulated that coarse particles favour crazing of the matrix, which absorbs energy, while small particles promote shearing of the polymer matrix, which again absorbs energy. The ultimate aim is to use the toughened polymer as a matrix for fibre-reinforced building materials. The potential of the building industry as a consumer of composites was stressed by $\mathrm{Dr} A$. J. Majumdar (Building Research Station, Watford), who showed how concrete or plaster panels could be toughened by incorporating (through a co-spraying technique) fibres of special zirconia-bearing glass which can stand up to the corrosive alkaline environment in concrete (there is no special problem with plaster). Majumdar explained that plaster panels thus reinforced will stand up to the repeated impact from primary school children.

Dr A. Kelly (National Physical Laboratory, Teddington) continued the theoretical approach by analysing the dependence of work of fracture on the length and diameter of fibres. It transpired, to the surprise of many, that from this point of view thick fibres were preferable. In brittle/ductile composites, thick fibres favour plastic deformation over large volumes of a ductile matrix, while in brittle/brittle composites, thick fibres suffer pull-out over greater lengths, with the increased associated frictional energy loss. Thus two physically quite distinct processes between them lead to a law of general validity for fibre composites.

Professor F. C. Frank (University of Bristol) assessed the ideal stiffness of a carbon chain by various means (infrared spectroscopy, calculations from the characteristics of diamond and so on) and was led to a value of 2-2.5 Mbar. The best value obtained in practice is apparently about ten times less than this, though it might have been predicted that hard-drawing, of nylon, for example, should reduce this factor of disparity. Frank went on to describe some special structures which seemed to consist of a stiff polymeric spine with built-in polymeric beads, which might open the way to a polymer-fibre-reinforced polymeric matrix. He predicted that quite soon the polymer industry, in search of higher strength, would turn to more elaborate production methods, even though this would diminish one of the chief advantages of polymers, their cheap fabrication. 